\title{
Atributos químicos no solo e produção de Cynodon dactylon cv. Tierra Verde sob doses de biofertilizante orgânico
}

\author{
Chemical attributes in soil and production of "Cynodon dactylon" cv. Tierra Verde on \\ doses of organic biofertilizer
}

\author{
SOARES FILHO, Cecilio Viega ${ }^{1 *}$; HEINRICHS, Reges ${ }^{2}$; PERRI, Silvia Helena \\ Venturoli $^{1}$; CORREIA, Amanda de Castro ${ }^{3}$
}

\author{
${ }^{1}$ Universidade Estadual Paulista, Faculdade de Medicina Veterinária, Departamento de Apoio, Produção e \\ Saúde Animal, Araçatuba, São Paulo, Brasil. \\ ${ }^{2}$ Universidade Estadual Paulista, Dracena, São Paulo, Brasil. \\ ${ }^{3}$ Engenheira Agrônoma, Mestre em Ciência Animal, Araçatuba, São Paulo, Brasil \\ *Endereço para correspondência: cecilio@fmva.unesp.br
}

\section{RESUMO}

A concentração de nutrientes na planta está relacionada ao solo, a adubação, o clima, a época, a cultivar e as práticas culturais. Com o objetivo de avaliar os atributos químicos do solo, a produção de massa seca da parte aérea e raízes, os teores de nutrientes na planta e a composição química do capim Tierra Verde submetido a doses de biofertilizante orgânico como fonte de nitrogênio, realizou-se um experimento em casa de vegetação da Faculdade de Medicina Veterinária, UNESP, Campus de Araçatuba-SP, de janeiro a setembro de 2010. Os tratamentos foram dispostos em delineamento inteiramente casualizado, adubados com seis doses de biofertilizante orgânico $\left(0 ; 33 ; 66 ; 132 ; 264 ; 528 \mathrm{~m}^{3} \mathrm{ha}^{-1}\right) \mathrm{e}$ com cinco repetições durante três cortes. Utilizou-se o modelo de parcelas subdivididas no tempo, sendo as doses de biofertilizante consideradas como tratamentos principais e os cortes como sub-parcelas. Foi obtida uma resposta linear na produção de massa seca da parte aérea e raízes até a dose de $528 \mathrm{~m}^{3} \mathrm{ha}^{-1}$ de biofertilizante orgânico. $\mathrm{O}$ biofertilizante orgânico influenciou nos atributos químicos do solo e nos teores da matéria orgânica, enxofre, boro e manganês, e nos teores foliares de fósforo, potássio e cobre. A composição bromatológica não foi alterada pela influência das doses de biofertilizante orgânico aplicado ao solo.

Palavras-chave: adubação orgânica, chorume bovino, gramíneas forrageiras, raízes, teor de nutrientes

\section{SUMMARY}

The concentration of nutrients in plant is related to the soil, fertilization, climate, season, cultivar and cultural practices. Aiming to evaluate the soil chemical properties, the dry matter production of shoots and roots, nutrient content in the plant and the chemical composition of the grass Tierra Verde subjected to levels of organic biofertilizer as nitrogen source, an experiment was conducted in a greenhouse at the Faculty of Veterinary Medicine, UNESP, Araçatuba-SP, January-September 2010. Treatments were arranged in a completely randomized design with six fertilized biofertilizer doses $(0,33,66$, $132,264,528 \mathrm{~m}^{3} \mathrm{ha}^{-1}$ ) and five repetitions for three cuts. We used the model split plot, with doses of biofertilizer considered as main treatments and cuts as sub-plots. We obtained a linear response in the production of dry mass of shoots and roots to the dose of $528 \mathrm{~m}^{3} \mathrm{ha}^{-1}$ of organic biofertilizer. Nitrogen fertilization influenced the soil chemical properties and levels of organic matter, sulfur, boron and manganese, and in foliar levels of phosphorus, potassium and copper. The chemical composition was not altered by the influence of organic biofertilizer doses applied to the soil.

Keywords: cattle manure, grasses, nutrient content, organic manure, roots 
Rev. Bras. Saúde Prod. Anim., Salvador, v.16, n.1, p.23-35 jan./mar., 2015 http://www.rbspa.ufba.br

\section{INTRODUÇÃO}

O lançamento de novas cultivares de gramíneas resulta da demanda crescente pela busca por plantas, que produzam forragem de alta qualidade, resistente ao pisoteio, bom vigor de rebrota e baixo custo de estabelecimento por sementes. Em atendimento a esta demanda foi desenvolvido o capim Tierra Verde, espécie de Cynodon dactylon. Devido à alta exigência de nitrogênio pelas culturas e pela atual necessidade deste nutriente ser usado de forma orgânica, o uso de fontes alternativas de nitrogênio, ou seja, de biofertilizante orgânico, como dejetos de bovinos, para a adubação de pastagens estão sendo estudados para diminuir a poluição ambiental, bem como reduzir os custos de produção, alicerçado no gerenciamento sustentável.

No Estado de São Paulo existe grande produção de bovinos em sistema de criação intensiva. Esse sistema caracteriza-se pelo confinamento dos animais e resulta em grande volume de dejetos líquidos, denominados chorume, um composto orgânico com elevado potencial fertilizante, constituído de fezes, urina, sobras de ração, água e outros resíduos que, quando adequadamente armazenados e corretamente utilizados, podem fornecer nutrientes para as plantas e melhorar as condições físico-químicas do solo.

O objetivo deste trabalho foi avaliar os atributos químicos do solo, a produção de massa seca (MS) da parte aérea e raízes, os teores de nutrientes na massa vegetal e a composição química do capim Cynodon dactylon cv. Tierra Verde adubado com doses de biofertilizante orgânico como fonte de nitrogênio.

\section{MATERIAL E MÉTODOS}

O experimento foi realizado no período de janeiro a setembro de 2010 em vasos, na casa de vegetação na Faculdade de Medicina Veterinária da UNESP, Campus de Araçatuba, SP, situada a $21^{\circ} 08^{\prime}$ de latitude sul, $50^{\circ} 25^{\prime}$ de longitude oeste e a $415 \mathrm{~m}$ de altitude. $\mathrm{O}$ biofertilizante orgânico utilizado no experimento provém de esterco, urina e restos de alimentos do barracão de alimentação das vacas leiteiras após ser fermentado anaerobicamente em biodigestor. $\mathrm{O}$ resultado analítico do efluente do biodigestor apresenta as seguintes características: carbono: $2.338 \mathrm{mg} \mathrm{L}^{-1}$, matéria orgânica (M.O.): $4.254 \mathrm{mg} \mathrm{L}^{-1}, \mathrm{~N}$ total: $420 \mathrm{mg} \mathrm{L}^{-1}$; $\mathrm{CaO}$ : $133 \mathrm{mg} \mathrm{L}^{-1} ; \mathrm{MgO}: 62 \mathrm{mg} \mathrm{L}^{-1} ; \mathrm{K}_{2} \mathrm{O}: 160 \mathrm{mg}$ $\mathrm{L}^{-1} ; \mathrm{P}_{2} \mathrm{O}_{5}: 56 \mathrm{mg} \mathrm{L}^{-1}$; relação $\mathrm{C} / \mathrm{N}: 5: 1 ; \mathrm{pH}$ $\mathrm{H}_{2} \mathrm{O}: 7,01$; e densidade de $1,0 \mathrm{~g} \mathrm{~L}^{-1}$.

Para cada unidade experimental foram utilizados quatro $\mathrm{dm}^{3}$ de terra classificada como Argissolo (EMBRAPA, 2013), coletada na camada de $0-20 \mathrm{~cm}$ de profundidade com os seguintes atributos químicos: $\mathrm{pH}\left(\mathrm{CaCl}_{2}\right)$ : 4,1; M.O.: $10 \mathrm{~g} \mathrm{dm}^{-3}$; P: $3 \mathrm{mg} \mathrm{dm}^{-3}$; K: 1,9 $\mathrm{mmol}_{\mathrm{c}} \mathrm{dm}^{-3}$; Ca: $6 \mathrm{mmol}_{\mathrm{c}} \mathrm{dm}^{-3} ; \mathrm{Mg}: 4$ $\mathrm{mmol}_{\mathrm{c}} \mathrm{dm}^{-3} ; \mathrm{H}+\mathrm{Al}: 47 \mathrm{mmol}_{\mathrm{c}} \mathrm{dm}^{-3}$; soma de bases: $11,9 \mathrm{mmol}_{\mathrm{c}} \mathrm{dm}^{-3}$ e capacidade de troca catiônica: $58,9 \mathrm{mmol}_{\mathrm{c}} \mathrm{dm}^{-3} \mathrm{e}$ saturação por bases (V): $20 \%$. A necessidade de calagem foi determinada pelo método de saturação por base para atingir o valor de $60 \%$ (QUAGGIO et al., 1985). A terra de cada vaso foi incubada com $\mathrm{CaCO}_{3}: \mathrm{MgCO}_{3}$ na relação de 3:1, durante 30 dias antes do plantio, recebendo neste período irrigação constante, mantendo-se a umidade em $80 \%$ da capacidade de campo.

Após o período de incubação, o solo foi novamente seco durante sete dias. A terra de cada vaso foi colocada em bandejas de plástico e adicionaram-se os seguintes 
nutrientes: $\mathrm{Ca}\left(\mathrm{H}_{2} \mathrm{PO}_{4}\right)_{2} \cdot \mathrm{H}_{2} \mathrm{O}, 200 \mathrm{mg} \mathrm{dm}^{-3}$ de $\mathrm{P} ; \mathrm{K}_{2} \mathrm{SO}_{4}, 150 \mathrm{mg} \mathrm{dm}^{-3}$ de $\mathrm{K}$ e $61,5 \mathrm{mg}$ $\mathrm{dm}^{-3}$ de $\mathrm{S} ; \mathrm{H}_{3} \mathrm{BO}_{3}, 0,5 \mathrm{mg} \mathrm{dm}{ }^{-3}$ de $\mathrm{B}$, $\mathrm{CuSO}_{4} .5 \mathrm{H}_{2} \mathrm{O}, 1 \mathrm{mg} \mathrm{dm}{ }^{-3}$ de $\mathrm{Cu} ; \mathrm{H}_{2} \mathrm{MoO}_{4}$, $0,1 \mathrm{mg} \mathrm{dm}^{-3}$ de $\mathrm{Mo} ; \mathrm{MnSO}_{4} \cdot \mathrm{H}_{2} \mathrm{O}, 3 \mathrm{mg}$ $\mathrm{dm}^{-3}$ de $\mathrm{Mn}$ e $\mathrm{ZnSO}_{4} .7 \mathrm{H}_{2} \mathrm{O}, 2 \mathrm{mg} \mathrm{dm}{ }^{-3}$ de $\mathrm{Zn}$. A fonte de potássio foi dividida em três aplicações, na semeadura e duas coberturas com o biofertilizante orgânico.

Após duas semanas a emergência do capim Tierra Verde foi realizada o desbaste mantendo oito plantas uniformes por vaso. Os vasos foram irrigados com água destilada diariamente para manter a umidade a $80 \%$ da capacidade de campo. A dose do biofertilizante foi dividida em quatro aplicações iguais. A primeira no dia da semeadura, e as demais 24 dias após a primeira aplicação, 21 dias após a segunda aplicação e 92 dias após a terceira aplicação. Foram realizados três cortes, o primeiro aos 37 dias após a semeadura, recebendo em cada tratamento, metade da dose total aplicada, o segundo 30 dias após o primeiro corte, recebendo $3 / 4$ da dose total aplicada, e o terceiro 140 dias após o segundo corte, recebendo a dosagem total dos tratamentos. O capim foi avaliado quando atingia a média de $25 \mathrm{~cm}$ de altura (medida pelo ângulo de inserção da folha mais alta), foi realizado o corte a $10 \mathrm{~cm}$ da superfície do solo. Após cada corte, o material foi identificado pesado e seco em estufa com ventilação forçada a $\pm 65^{\circ} \mathrm{C}$ por $72 \mathrm{~h}$ (SILVA \& QUEIROZ, 2002) para a determinação da produção de massa seca. Depois de secas as amostras foram moídas em moinho tipo Wiley e realizadas as análises bromatológicas e a concentração dos nutrientes foliares.

Foram determinados os teores dos tecidos foliares de $\mathrm{N}, \mathrm{P}, \mathrm{K}, \mathrm{Ca}, \mathrm{Mg}, \mathrm{Cu}$, $\mathrm{Fe}, \mathrm{Mn}$ e Zn. A concentração de proteína bruta $(\mathrm{PB})$ foi determinada, multiplicando-se o teor de $\mathrm{N}(\%)$ por 6,25. As análises seguiram a metodologia descrita por Malavolta et al. (1997). As frações de fibra em detergente neutro (FDN) e fibra em detergente ácido (FDA) foram determinadas pelo método de Campos et al. (2004).

As raízes foram coletadas ao término do experimento, sendo estas lavadas em água corrente até retirar todo o solo existente, utilizando-se peneiras de malha de dois $\mathrm{mm}$ e posteriormente passadas em água deionizada. Para determinar a massa seca das raízes as amostras foram devidamente identificadas, ensacadas e em seguida, colocou-se o material para secar conforme descrito anteriormente.

Foram coletadas amostras de solo ao final do experimento para realizar análise química para determinar os valores de matéria orgânica $(\mathrm{MO}), \mathrm{pH}$, $\mathrm{P}, \mathrm{K}, \mathrm{Ca}, \mathrm{Mg}, \mathrm{Al}, \mathrm{H}+\mathrm{Al}$, soma de bases (SB), capacidade de troca catiônica (CTC), saturação por base (V), S, B, $\mathrm{Cu}, \mathrm{Fe}, \mathrm{Mn}$ e $\mathrm{Zn}$.

O delineamento experimental foi inteiramente casualizado, com cinco repetições, arranjados em parcelas subdivididas, com medidas repetidas no tempo. Nas parcelas principais, encontravam-se as doses de biofertilizante orgânico $(0 ; 33 ; 66 ; 132$; 264 e $\left.528 \mathrm{~m}^{3} \mathrm{ha}^{-1}\right)$. Essas doses corresponderam à aplicação de $0 ; 14 ; 28$; $56 ; 111 ; 222 \mathrm{~kg} \mathrm{ha}^{-1}$ de N. Os dados foram testados quanto à normalidade dos erros $\mathrm{e}$ homogeneidade de variâncias e as análises estatísticas foram realizadas utilizando-se o programa SAS, versão 9.1 (STATISTICAL ANALYSIS SYSTEMS, 1999), no procedimento GLM para o modelo de parcelas subdivididas no tempo, sendo as doses de biofertilizante consideradas como tratamento principal e os cortes como sub-parcela. Os resultados foram submetidos à ANOVA e teste SNK (Student-Newman-Keuls) para a comparação múltipla de médias, a 5\% 
Rev. Bras. Saúde Prod. Anim., Salvador, v.16, n.1, p.23-35 jan./mar., 2015 http://www.rbspa.ufba.br

de significância. Foram realizadas análises de regressão em função das doses de biofertilizante orgânico.

\section{RESULTADOS E DISCUSSÃO}

A produção de massa seca (MS) dos cortes do capim Tierra Verde não apresentou significância na análise de variância entre as doses de biofertilizante, no entanto, foi verificada interação significativa entre as doses e cortes $(p>0,0001)$. Desdobrando a interação pode-se observar que existe diferença significativa entre as doses somente para o terceiro corte de MS, e na produção de MS total, que segue uma equação linear, ou seja, o capim Tierra Verde respondeu linearmente até a dose de $528 \mathrm{~m}^{3} \mathrm{ha}^{-1}$ de biofertilizante orgânico (Figura 1a). Foi observado aumento na produção de MS a partir das doses de 66 até $528 \mathrm{~m}^{3} \mathrm{ha}^{-1}$ de biofertilizante orgânico. Para o primeiro e segundo ciclo de crescimento do capim, não houve resposta de aplicação das doses estudadas.
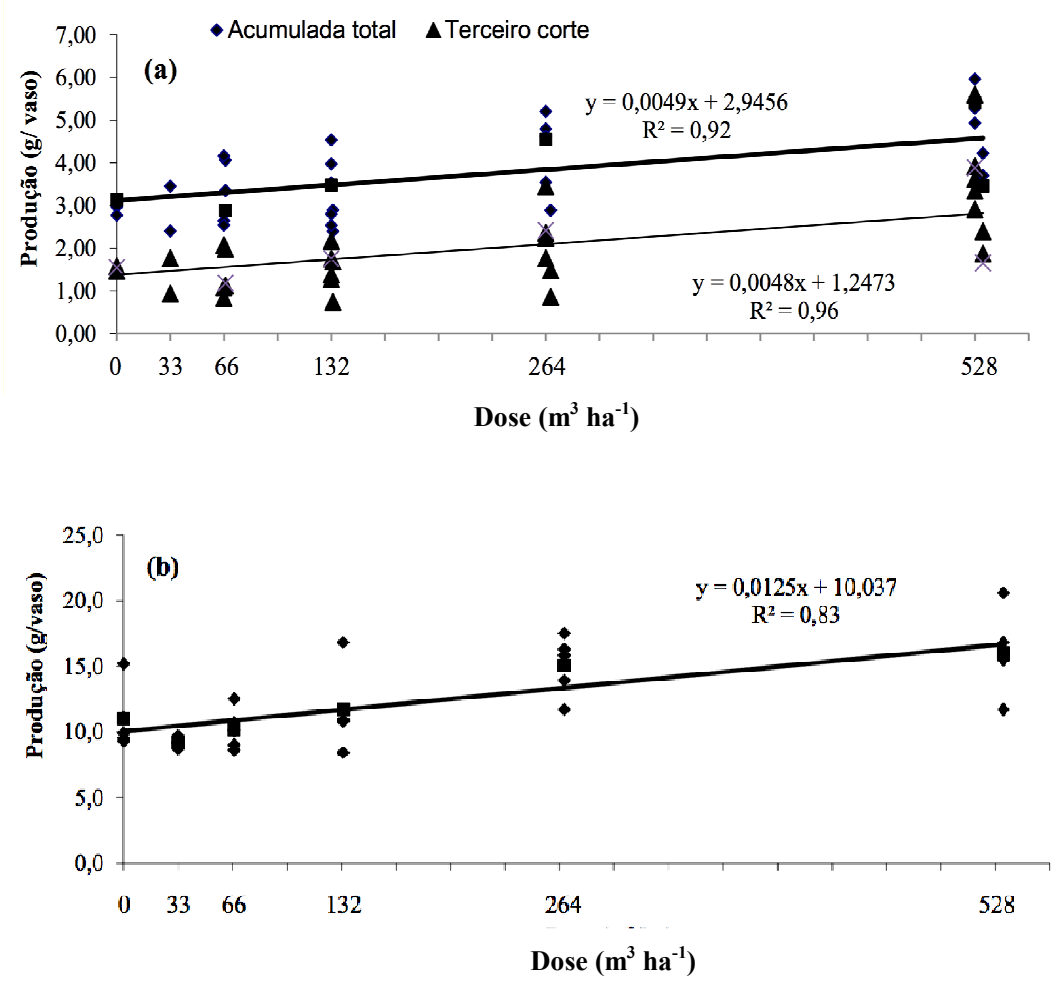

Figura 1. Produção de massa seca terceiro corte e total de Cynodon dactylon cv. Tierra Verde (a) e massa seca das raízes $\left(\mathrm{g}\right.$ vaso $\left.^{-1}\right)(\mathrm{b})$, em função das doses de biofertilizante orgânico $\left(\mathrm{m}^{3} \mathrm{ha}^{-1}\right) * \mathrm{p}<0,05$

Os melhores resultados, independentemente da dose, foram no terceiro corte, provavelmente em razão das adequadas condições de fertilidade ocasionada pela adubação com o biofertilizante orgânico e também pelas adequadas temperaturas e intervalo maior de corte em relação aos anteriores. O maior intervalo de corte ocorreu devido à redução da temperatura após o segundo 
corte, paralisando o crescimento das plantas devido à ocorrência de baixas temperaturas, reduzindo a rebrota com temperatura base abaixo de $12^{\circ} \mathrm{C}$ (VILLA NOVA et al., 2004). Resultados semelhantes foram encontrados por Schimidt et al. (2003), ao estudarem o efeito das doses zero; 60; 120 e $180 \mathrm{~kg}$ ha $^{-1}$ de $\mathrm{N}$, na forma de biofertilizante orgânico, com o Megathyrsus maximum cv. Tanzânia os autores observaram que a massa seca da parte aérea foi maior nos vasos adubados com maiores doses de biofertilizante orgânico no terceiro corte, aos 84 dias após plantio.

No primeiro corte as doses de biofertilizante orgânico aplicado (1/2 da dose de cada tratamento) foram insuficientes para $\mathrm{o}$ aumento da produção de massa seca. A menor produção de MS ocorreu no segundo corte, podendo ser atribuído a menor taxa de crescimento durante a rebrota no período. Resultados semelhantes foram observados por Silva Neto et al. (2010), que verificaram aumentos na produção de MS do capim-Marandu de acordo com as doses $(37,5 ; 75$ e $112,5 \mathrm{~m}^{3} \mathrm{ha}^{-1}$ ) do biofertilizante oriundo de resíduo líquido de frigorífico, no entanto, a maior produção de MS total foi encontrada no primeiro corte, quando comparado ao segundo. Martuscello et al. (2006; 2005), também encontraram dados semelhantes da produção acumulada de MS da parte aérea do Megathyrsus maximum cv. Massai e Urochloa brizantha cv. Xaraés, respectivamente, submetidos a doses de N. Drumond et al. (2006), observaram que ao utilizar doses crescentes de dejeto líquido de suíno na produção de massa seca pré-pastejo de Cynodon spp. cv. Tifton 85 , até a dose de $200 \mathrm{~m}^{3} \mathrm{ha}^{-1}$ ocorreu acréscimo na produção de acordo com o aumento das doses de fertilizante orgânico.
Para a produção de massa seca das raízes após os cortes, coletadas ao final do experimento, houve efeito significativo das doses de biofertilizante orgânico $(p<0,0005)$. Pela análise de variância, verificou-se o efeito linear das doses crescentes de biofertilizante orgânico sobre a MS das raízes, sendo que a máxima produção foi com a maior dose de biofertilizante orgânico (Figura 1b). Schimidt et al. (2003), além da produção de massa seca da parte aérea, citado anteriormente, encontraram também a maior produção de MS das raízes na maior dose estudada de $180 \mathrm{~kg}$ $\mathrm{ha}^{-1}$ de $\mathrm{N}$ na forma de biofertilizante. Quanto aos atributos químicos do solo observou-se diferença significativa $(\mathrm{p}<0,05)$ entre as doses para as variáveis M.O., S, B e Mn (Figura 2). Não se observou diferença significativa $(\mathrm{p}>0,05)$ entre as doses para as variáveis $\mathrm{pH}, \mathrm{P}, \mathrm{K}$, $\mathrm{Ca}, \mathrm{Mg}, \mathrm{H}+\mathrm{Al}$, soma de bases (SB), capacidade de troca de cátions (CTC), saturação por bases $(\mathrm{V}), \mathrm{Cu}, \mathrm{Fe}$ e $\mathrm{Zn}$ (Tabela 1).

A maior concentração de matéria orgânica no solo foi encontrada no tratamento que não recebeu a adubação com o biofertilizante orgânico. Os vasos que receberam as doses do efluente tiveram redução nestes teores. Esse resultado é atribuído ao aumento na atividade microbiana no solo motivado pelo aumento da disponibilidade de nitrogênio no solo com a aplicação de biofertilizante (Figura 2a), favorecendo a produção de MS da parte aérea e raiz (Figura 1). Brito et al. (2008) estudando a transformação da matéria orgânica e do nitrogênio durante a compostagem da fração sólida do chorume bovino estáticas e em pilhas com revolvimento, concluindo que o teor de M.O. diminuiu em todas as pilhas de compostagem. 
Rev. Bras. Saúde Prod. Anim., Salvador, v.16, n.1, p.23-35 jan./mar., 2015 http://www.rbspa.ufba.br

Tabela 1.Médias e desvio padrão (s) dos atributos químicos do solo após três cortes de Cynodon dactylon cv. Tierra Verde adubado com doses de biofertilizante orgânico

\begin{tabular}{lccc}
\hline Variável & Médias $\pm \mathrm{s}$ & Variável & Médias $\pm \mathrm{s}$ \\
\hline $\mathrm{pH}$ & $6,03 \pm 0,20$ & $\mathrm{SB}\left(\mathrm{mmol}_{\mathrm{c}} \mathrm{dm}^{-3}\right)^{(1)}$ & $45,27 \pm 0,18$ \\
$\mathrm{P}\left(\mathrm{g} \mathrm{dm}^{-3}\right)$ & $92,47 \pm 0,19$ & $\mathrm{CTC}\left(\mathrm{mmol}_{\mathrm{c}} \mathrm{dm}^{-3}\right)^{(2)}$ & $62,91 \pm 0,25$ \\
$\mathrm{~K}\left(\mathrm{mmol}_{\mathrm{c}} \mathrm{dm}^{-3}\right)$ & $3,47 \pm 0,31$ & $\mathrm{~V}(\%)^{(3)}$ & $71,63 \pm 0,09$ \\
$\mathrm{Ca}\left(\mathrm{mmol}_{\mathrm{c}} \mathrm{dm}^{-3}\right)$ & $29,10 \pm 0,19$ & $\mathrm{Cu}\left(\mathrm{mg} \mathrm{dm}^{-3}\right)$ & $1,20 \pm 0,11$ \\
$\mathrm{Mg}\left(\mathrm{mmol}_{\mathrm{c}} \mathrm{dm}^{-3}\right)$ & $12,70 \pm 0,23$ & $\mathrm{Fe}\left(\mathrm{mg} \mathrm{dm}^{-3}\right)$ & $16,00 \pm 0,05$ \\
$\mathrm{H}+\mathrm{Al}\left(\mathrm{mmol}_{\mathrm{c}} \mathrm{dm}^{-3}\right)$ & $17,63 \pm 0,09$ & $\mathrm{Zn}\left(\mathrm{mg} \mathrm{dm}^{-3}\right)$ & $1,01 \pm 0,17$ \\
\hline
\end{tabular}

${ }^{(1)} \mathrm{SB}=$ soma de bases; $;{ }^{(2)} \mathrm{CTC}=$ capacidade de troca catiônica; ${ }^{(3)} \mathrm{V}=$ saturação por base.
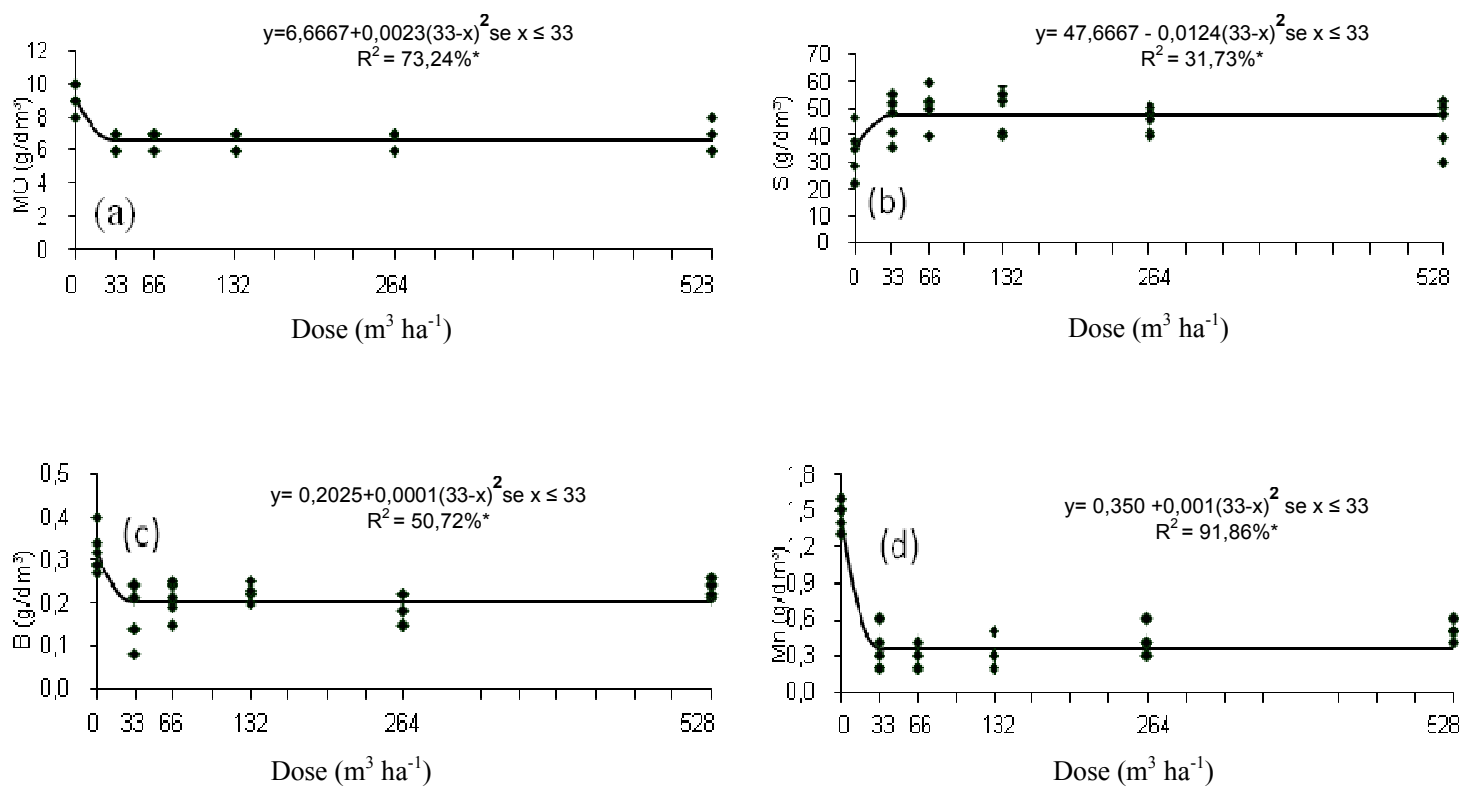

Figura 2. Teor de matéria orgânica (a), enxofre (b), boro (c) e manganês (d) no solo dos vasos adubados com biofertilizante orgânico $* \mathrm{P}<0,05$

O teor de boro (B) no solo diminuiu com aplicação das doses de biofertilizante em relação ao tratamento testemunha. A principal fonte de B no solo é a M.O., confirmando os resultados encontrados, uma vez que neste experimento, as concentrações da M.O. reduziram (Figura 2c), atribuída a maior atividade microbiana do solo com a introdução de $\mathrm{N}$ no sistema por meio da aplicação do biofertilizante. De acordo com o resultado, os valores dos teores de $\mathrm{B}$ no solo, variaram de baixo $\left(0,16 \mathrm{mg} \mathrm{dm}^{-3}\right)$ a médio $\left(0,32 \mathrm{mg} \mathrm{dm}^{-3}\right)$ em função da doses aplicada. Os teores de $\mathrm{Mn}$ diminuíram com a aplicação das doses do biofertilizante quando comparados ao tratamento testemunha (Figura 2d), pois segundo Raij et al. (1997) os teores de $\mathrm{Mn}$ no solo variaram de baixo $\left(0,26 \mathrm{mg} \mathrm{dm}^{-3}\right)$ a médio $\left(1,46 \mathrm{mg} \mathrm{dm}^{-3}\right)$ em função dos tratamentos. 
O índice de $\mathrm{pH}$ do solo variou de 5,9 a 6,3 e não sofreu variação com a aplicação do biofertilizante orgânico, o que geralmente ocorre com o uso de fertilizantes nitrogenados minerais. Como verificado por Costa et al. (2008), na aplicação de sulfato de amônio e ureia em capim-Marandu, Primavesi et al. (2005), com aplicação de ureia e nitrato de amônio em capim-Coastcross e por Lange et al. (2006), com aplicação da ureia na cultura do milho. A digestão anaeróbica (biofertilizante) apresentando pequena variação na reação do solo por se tratar de um produto estabilizado biologicamente (KIEHL, 1985). Resultados similares foram obtidos por Raschid et al. (2014) aplicando esterco bovino sólido na dose de $200 \mathrm{~kg} \mathrm{ha}^{-1} \mathrm{de}$ $\mathrm{N}$ em pastagem de azevém perene não encontraram efeito sobre o $\mathrm{pH}$ do solo.

Os teores de $\mathrm{P}, \mathrm{K}, \mathrm{Ca}$ e $\mathrm{Mg}$ no solo apresentaram, respectivamente, as amplitudes de 80,2 a $116,4 \mathrm{mg} \mathrm{dm}^{-3}, 3,2$ a $3,9 \mathrm{mmol}_{\mathrm{c}} \mathrm{dm}^{-3}, 26,8$ a $33,6 \mathrm{mmol}_{\mathrm{c}}$ $\mathrm{dm}^{-3}, 11,4$ a $13,6 \mathrm{mmol}_{\mathrm{c}} \mathrm{dm}^{-3}$, todos considerados altos segundo Raij et al. (1997). Por sua vez, a saturação por bases apresentou valores que variaram de média (51-70) a alta (71-90) 69,6 a $74,6 \%$, sendo considerados teores adequados para o bom desenvolvimento da espécie forrageira.

Em relação aos micronutrientes no solo, o $\mathrm{Cu}$ e o $\mathrm{Fe}$ apresentaram teores altos, variando respectivamente de 1,18 a $1,28 \mathrm{mg} \mathrm{dm}^{-3}, 14,8$ a $16,8 \mathrm{mg} \mathrm{dm}^{-3}$. Para o $\mathrm{Zn}$ os valores variaram de 0,9 a $1,1 \mathrm{mg}$ $\mathrm{dm}^{-3}$, compreendendo a faixa considerada como média disponibilidade no solo (RAIJ et al., 1997). Esses resultados evidenciam que a adubação de plantio atendeu as necessidades nutricionais para o capim Tierra Verde.

Pela análise de variância, observou-se interação significativa entre doses $\mathrm{e}$ cortes para as variáveis $\mathrm{P}$ e $\mathrm{Zn}$ (Figura 3). Desdobrando a interação, para a variável $\mathrm{P}$ existe diferença significativa entre os cortes para as doses de 66 e 528 $\mathrm{m}^{3} \mathrm{ha}^{-1}$. No primeiro corte os teores variaram de 2,70 a $3,35 \mathrm{~g} \mathrm{~kg}^{-1}$ na planta (Figura 3a), e as doses seguem uma equação quadrática e no terceiro corte os teores variou de 2,15 a $3,35 \mathrm{~g} \mathrm{~kg}^{-1}$ na planta, seguindo uma equação quadrática. $\mathrm{O}$ teores de $\mathrm{P}$ na planta nos dois cortes estão próximos ao limite crítico superior da faixa considerada adequada para o capim Cynodon (1,5 a $\left.3,0 \mathrm{~g} \mathrm{~kg}^{-1}\right)$, segundo Werner et al. (1997).

$\mathrm{Na}$ avaliação do terceiro corte, (Figura 3a), houve decréscimo nos teores de $\mathrm{P}$ encontrados após a aplicação do biofertilizante orgânico. Resultados semelhantes foram encontrados por Primavesi et al. (2006), que estudaram o efeito de doses de $\mathrm{N}$ na fitomassa do capim-Marandu e concluíram que o $\mathrm{N}$ na forma de ureia diminuiu os teores de $\mathrm{P}$, e quando aplicado na forma de nitrato de amônio, os teores de $\mathrm{P}$ não variaram.

Reijneveld et al. (2014) estudando as relações entre fertilidade do solo, qualidade de forragem e composição do esterco aplicado em áreas de pastagens de fazendas leiteiras, encontraram correlações lineares positivas com o S, $\mathrm{P}, \mathrm{K}$ e $\mathrm{Mg}$ no solo e na pastagem.

Para a variável $\mathrm{Zn}$, existe diferença significativa $(\mathrm{P}<0,05)$ entre os cortes para as doses $0,33,66$ e $264 \mathrm{~m}^{3} \mathrm{ha}^{-1}$ (Figura 3b). Os teores variam de 37 a $59 \mathrm{mg} \mathrm{kg}^{-1}$ no primeiro corte e de 58 a $71 \mathrm{mg} \mathrm{kg}^{-1}$ no terceiro corte. De acordo com Werner et al. (1997), os teores podem variar de 15 a $70 \mathrm{mg} \mathrm{kg}^{-1}$ para serem considerados adequados. Primavesi et al. (2006), encontrou respostas lineares e quadráticas no capim-Marandu para as fontes de ureia e nitrato de amônio, respectivamente para os teores de $\mathrm{Zn}$, onde em relação ao tratamento testemunha, os teores aumentaram 5,3 e 6,9 mg kg $\mathrm{mara}^{-1}$ cada fonte nitrogenada estudada. 
Rev. Bras. Saúde Prod. Anim., Salvador, v.16, n.1, p.23-35 jan./mar., 2015 http://www.rbspa.ufba.br
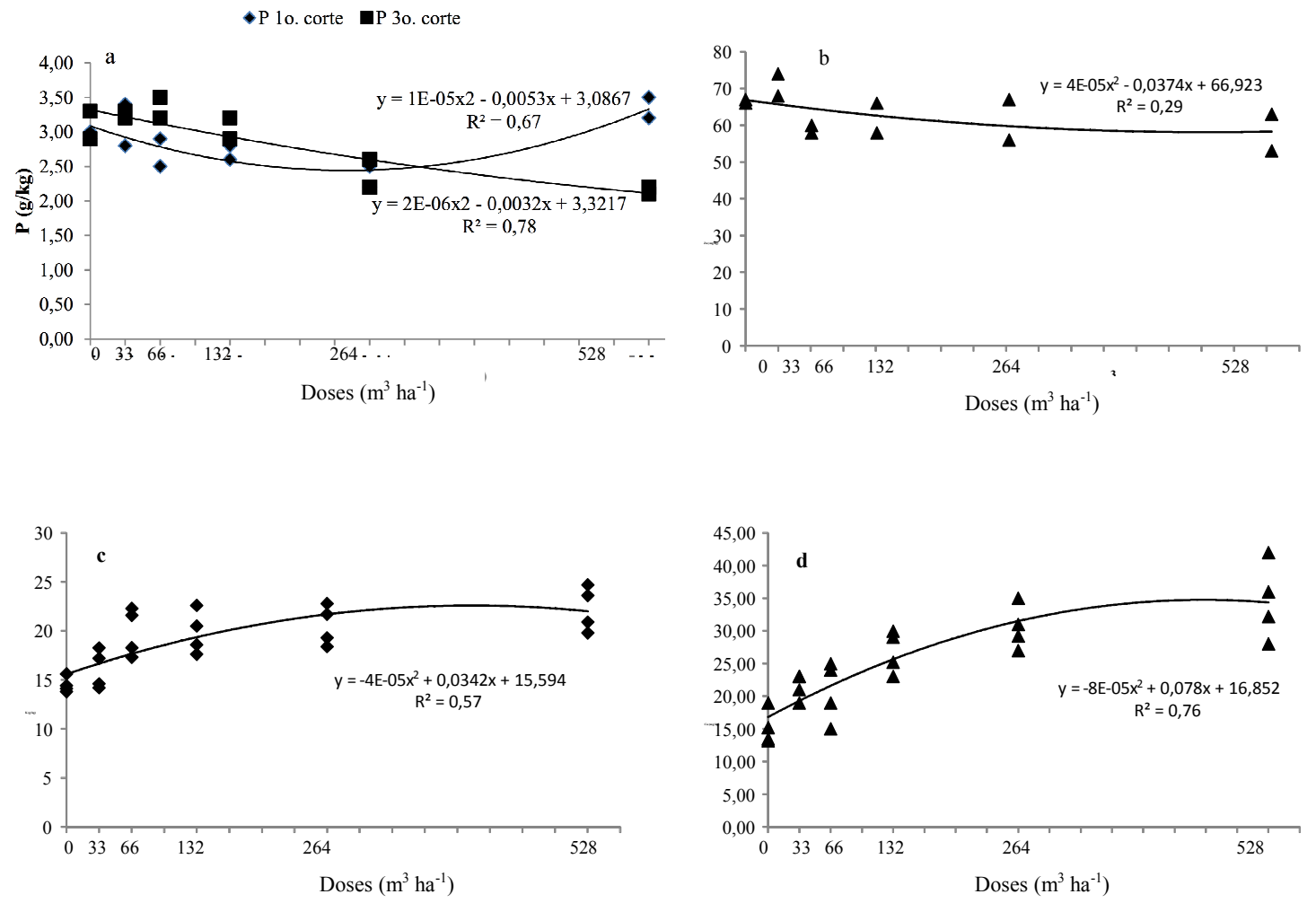

Figura 3. Teores de P na parte aérea das plantas após a aplicação do biofertilizante orgânico no capim Tierra Verde, no primeiro (a) e terceiro corte (b), teores de $\mathrm{K}$ (c) e $\mathrm{Cu}(\mathrm{d})$ nos dois cortes *p $>0,05$

Para as variáveis $\mathrm{N}, \mathrm{Ca}, \mathrm{Mg}, \mathrm{Mn}$ e $\mathrm{Fe}$ na parte aérea, não observou-se diferença significativa $(\mathrm{p}>0,05)$ entre as doses, apresentando diferença apenas entre as doses para as variáveis $\mathrm{K}$ e $\mathrm{Cu}$ (Tabela 2). Os teores de $\mathrm{N}$ na parte aérea deste experimento variaram de 8,85 a $9,65 \mathrm{~g} \mathrm{~kg}^{-1}$. Estes teores estão abaixo da faixa adequada para o capim do gênero Cynodon, que deve variar entre 20 a $26 \mathrm{~g} \mathrm{~kg}^{-1}$, segundo Werner et al. (1997). Em pastagens adubadas com biofertilizante a sua deficiência de $\mathrm{N}$ na planta pode ser explicada pela maior imobilização durante a decomposição de resíduos orgânicos e pelo maior tempo requerido nas taxas de mineralização da M.O. Em experimentos de curta duração também ocorre que a M.O. seria capaz de reduzir o impacto das perdas porque cerca de $40 \%$ do $\mathrm{N}$ fica imobilizado nos tecidos e raízes, na coroa da planta e na microbiota do solo, sendo passível de reciclagem. Do total de $\mathrm{N}$ aplicado, a planta pode recuperar $70 \%$ a médio e longo prazo (AGUIAR, 2011).

Raschid et al. (2014) avaliando a aplicação de esterco bovino sólido na dose de $200 \mathrm{~kg} \mathrm{ha}^{-1}$ de $\mathrm{N}$ encontraram aumento cumulativo do $\mathrm{N}$ absorvido $26 \%$ superior quando comparado ao tratamento não fertilizado em pastagem de azevém perene.

$\mathrm{O}$ teor de $\mathrm{K}$ na planta no primeiro corte, aumentou com a aplicação do biofertilizante orgânico, quando comparado ao tratamento testemunha. No terceiro corte o maior teor também foi encontrado na dose de $528 \mathrm{~m}^{3}$ ha $^{-1}$ (Figura $3 c)$. Ocorreu à diminuição no teor de $\mathrm{K}$ no terceiro corte, quando comparado ao primeiro (Tabela 2). Esta diferença entre 
Rev. Bras. Saúde Prod. Anim., Salvador, v.16, n.1, p.23-35 jan./mar., 2015 http://www.rbspa.ufba.br

os cortes se deve provavelmente ao aumento do biofertilizante no solo, aumentando o teor de $\mathrm{N}$ e diminuindo o teor de $\mathrm{K}$. Os teores de $\mathrm{K}$ variaram de 17,58 a $19,75 \mathrm{~g} \mathrm{~kg}^{-1}$, estes dados estão de acordo com os encontrados por Werner et al. (1997). Batista \& Monteiro (2010) explicam que quando há aplicação de doses de $\mathrm{N}$ maiores que $200 \mathrm{mg} \mathrm{dm}^{-3}$, ocorre diminuição do teor de $\mathrm{K}$ na parte aérea da planta, causado pelo efeito de diluição. No presente experimento as duas doses maiores de $\mathrm{N}$ corresponderam a 222 e $442 \mathrm{mg} \mathrm{dm}^{-3}$, estando acima do relatado pelos autores.

Tabela 2. Médias e desvio padrão (s) do teor de nutrientes da parte aérea de Cynodon dactylon cv. Tierra Verde adubado com doses de biofertilizante orgânico

\begin{tabular}{lccc}
\hline Variável & Média $\pm \mathrm{s}$ & Corte 1 & Corte 3 \\
\hline $\mathrm{N}\left(\mathrm{g} \mathrm{kg}^{-1}\right)$ & $9,65 \pm 2,87$ & $11,48 \pm 1,02^{\mathrm{A}}$ & $7,26 \pm 0,51^{\mathrm{B}}$ \\
$\mathrm{K}\left(\mathrm{g} \mathrm{kg}^{-1}\right)$ & $17,68 \pm 4,22$ & $22,21 \pm 1,22^{\mathrm{A}}$ & $14,40 \pm 0,60^{\mathrm{B}}$ \\
$\mathrm{Ca}\left(\mathrm{g} \mathrm{kg}^{-1}\right)$ & $5,03 \pm 1,58$ & $3,64 \pm 0,79^{\mathrm{B}}$ & $5,56 \pm 0,52^{\mathrm{A}}$ \\
$\mathrm{Mg}\left(\mathrm{g} \mathrm{kg}^{-1}\right)$ & $2,60 \pm 0,36$ & $2,23 \pm 0,29^{\mathrm{B}}$ & $2,54 \pm 0,30^{\mathrm{A}}$ \\
$\mathrm{Cu}\left(\mathrm{mg} \mathrm{kg}^{-1}\right)$ & $13,5 \pm 8,9$ & $17,8 \pm 7,9^{\mathrm{B}}$ & $28,3 \pm 6,8^{\mathrm{A}}$ \\
$\mathrm{Fe}\left(\mathrm{mg} \mathrm{kg}^{-1}\right)$ & $220,5 \pm 140,9$ & $93,3 \pm 34,1^{\mathrm{B}}$ & $318,9 \pm 67,1^{\mathrm{A}}$ \\
$\mathrm{Mn}\left(\mathrm{mg} \mathrm{kg}^{-1}\right)$ & $165,0 \pm 39,5$ & $127,3 \pm 127,3^{\mathrm{B}}$ & $204,1 \pm 204,1^{\mathrm{A}}$ \\
\hline
\end{tabular}

Médias, nas linhas, seguidas de letras maiúsculas distintas diferem $(\mathrm{p} \leq 0,05)$ entre si elo teste de médias de SNK.

Os teores de Ca variaram de 4,15 a 5,08 g $\mathrm{kg}^{-1}$, resultados considerados adequados $\left(3-8 \mathrm{~g} \mathrm{~kg}^{-1}\right)$ de acordo com Werner et al. (1997). Os teores de $\mathrm{Mg}$ foram considerados na faixa ideal $\left(1,5 \mathrm{a} 4 \mathrm{~g} \mathrm{~kg}^{-}\right.$ ${ }^{1}$ ), pois variaram de $2,08 \mathrm{a} 2,60 \mathrm{~g} \mathrm{~kg}^{-1}$.

Os teores micronutrientes de manganês $(\mathrm{Mn})$ variaram de 161,8 a $171,5 \mathrm{mg} \mathrm{kg}^{-1}$, e segundo Werner et al. (1997), estes teores estão dentro da faixa de concentração adequada. Os teores de Fe e $\mathrm{Cu}$, respectivamente, de 183,5 a $220,5 \mathrm{mg} \mathrm{kg}^{-1}$, e de 13,5 a $32,3 \mathrm{mg} \mathrm{kg}^{-1}$, estão acima da faixa considerada adequada (WERNER et al., 1997). Observa-se que os teores de $\mathrm{Cu}$ aumentaram de forma quadrática com a aplicação do biofertilizante orgânico (Figura 3d). Primavesi et al. (2004), também encontraram resultados semelhantes onde os teores de $\mathrm{Cu}$ aumentaram de forma linear com aplicação de $\mathrm{N}$ na forma de ureia e quadrática com nitrato de amônio.

Os teores de proteína bruta (PB) variaram de 5,53 a $6,22 \%$ e não apresentaram diferença significativa, $(\mathrm{P}>0,05)$, entre as doses estudadas de biofertilizante orgânico (Tabela 3). Rocha et al. (2002), também não verificaram o efeito nos teores de PB em função das doses de nitrogênio, aplicadas em gramíneas do gênero Cynodon. Rodrigues et al. (2006), avaliaram o teor de $\mathrm{PB}$ em cinco cultivares de Cynodon (Tifton 85, Florakirk, Tifton 68, Florona e Florico) aos $14 ; 28 ; 42 ; 56$ e 76 dias de idades das plantas, e obtiveram uma média de $14,4 \%$, sendo esses valores superiores aos encontrados neste trabalho. Os valores encontrados neste experimento foram 
Rev. Bras. Saúde Prod. Anim., Salvador, v.16, n.1, p.23-35 jan./mar., 2015 http://www.rbspa.ufba.br

considerados baixos para a espécie estudada quando comparados com os dados da literatura.

Reijeneveld et al. (2014) não encontraram efeito da aplicação de esterco em pastagens de fazendas leiteiras durante 20 anos sobre a qualidade da forragem que em média obtiveram teor de FDN $(72 \% \pm$ $4,07)$ e o teor de PB diminuiu ao longo dos anos.

Tabela 3. Médias e desvio (s) padrão dos teores de proteína bruta (PB), fibra em detergente neutro (FDN) e fibra em detergente ácido (FDA) do capim Tierra Verde em função da aplicação das doses do biofertilizante orgânico

\begin{tabular}{lccc}
\hline \multirow{2}{*}{ Doses $\left(\mathrm{m}^{3} \mathrm{ha}^{-1}\right)$} & PB (\%) & FDN $(\%)$ & FDA (\%) \\
& $\overline{\mathrm{x}} \pm \mathrm{s}$ & $\overline{\mathrm{x}} \pm \mathrm{s}$ & $\overline{\mathrm{x}} \pm \mathrm{s}$ \\
\hline 0 & $6,03 \pm 0,29$ & $73,63 \pm 1,11$ & $34,46 \pm 0,96$ \\
33 & $6,22 \pm 0,31$ & $73,55 \pm 0,55$ & $34,12 \pm 0,17$ \\
66 & $5,53 \pm 0,24$ & $73,96 \pm 1,33$ & $34,12 \pm 1,09$ \\
132 & $5,75 \pm 0,20$ & $73,22 \pm 0,20$ & $34,28 \pm 0,11$ \\
264 & $5,65 \pm 0,18$ & $75,70 \pm 0,35$ & $34,70 \pm 0,33$ \\
528 & $5,94 \pm 0,29$ & $74,35 \pm 0,52$ & $34,74 \pm 0,16$ \\
\hline
\end{tabular}

Para os teores de fibra em detergente neutro (FDN) e fibra em detergente ácido (FDA), (Tabela 3) não se observou diferença significativa ( $>00,05)$ após a aplicação do biofertilizante orgânico. Os valores de FDN encontrados, acima de $70 \%$, são concordantes com os relatados por outros autores. Resultados semelhantes foram encontrados por Rodrigues et al. (2006), avaliando cinco cultivares de Cynodon, que encontraram uma média de $76,1 \%$ de FDN.

Orrico Junior et al. (2013) avaliando doses de biofertilizantes $(0 ; 100 ; 200$ e $300 \mathrm{~kg}^{-1}$ de N) no valor nutritivo do Urochloa brizantha cv. Piatã para os teores de FDN, FDA, celulose, hemicelulose e lignina apresentaram comportamento linear negativo em função das doses crescentes de N. Os teores de PB de digestibilidade in vitro da matéria seca responderam linearmente.

Van Soest (1994) destacou a importância dos valores de FDN para verificar a qualidade dos valores de FDN para verificar a qualidade das plantas forrageiras. $\mathrm{O}$ autor estabeleceu que os teores de FDN superiores a 60\% da MS associam-se negativamente à capacidade de consumo voluntário da forragem pelos animais e consequentemente, reduzem o desempenho animal. Os dados obtidos neste experimento o capim Tierra Verde apresentaria limitação no consumo voluntário dos animais (FDN maior que $60 \%$ ).

Rocha et al. (2002), avaliando doses de $\mathrm{N}$ em gramíneas do gênero Cynodon encontraram teores médios de FDA, independente das doses de nitrogênio, de $40,38 \% ; \quad 40,68 \%$ e $39,49 \%$, respectivamente para os capins Coastcross, Tifton 68 e Tifton 85, valores superiores aos encontrados neste trabalho. Soares Filho et al. (2002), estudaram teores de FDA em sete cultivares de Cynodon (Tifton 68, Tifton 78, Tifton 85, Florakirk, Florico, Florona, Coastcross), obtendo em média $40,1 \%$ na estação das águas e $38,9 \%$ na estação da seca, sendo que os valores em ambas as estações encontram-se acima da média deste trabalho.

Com a aplicação de doses de biofertilizante orgânico verificou-se resposta linear na produção acumulada 
Rev. Bras. Saúde Prod. Anim., Salvador, v.16, n.1, p.23-35 jan./mar., 2015 http://www.rbspa.ufba.br ISSN 15199940

de massa seca da parte aérea e raízes até a dose de $528 \mathrm{~m}^{3} \mathrm{ha}^{-1}$ de biofertilizante orgânico. O biofertilizante orgânico influenciou nos atributos químicos do solo e nos teores da matéria orgânica, enxofre, boro e manganês, e nos teores foliares de fósforo, potássio, zinco e cobre. No entanto, a composição bromatológica não foi alterada pela influência das doses de biofertilizante orgânico aplicado ao solo.

\section{REFERÊNCIAS}

AGUIAR, A. P. A. Correção e adubação do solo da pastagem. Uberaba, 2011. 246p.

BATISTA, K.; MONTEIRO, F. A. variações nos teores de potássio, cálcio e magnésio em capim-marandu adubado com doses de nitrogênio e de enxofre.

Revista Brasileira Ciência do Solo, v.34, p.151-161, 2010.

BRITO, L. M.; AMARO, A. L.; MOURÃO, I.; COUTINHO, J.

Transformação da matéria orgânica e do nitrogênio durante a compostagem da fração sólida do chorume bovino.

Revista Brasileira Ciência do Solo, v.32, p.1959-1968, 2008.

CAMPOS, F. B.; NUSSIO, C. M. B.\& NUSSIO, L. G. Métodos de análises de alimentos. Piracicaba: Fundação de Estudos Agrários Luiz de Queiroz, 2004. 135p.

COSTA K. A. P.; FAQUIN, V.; OLIVEIRA, I. P.; RODRIGUES, C.; SEVERIANO, E. C. Doses e fontes de nitrogênio em pastagem de capimMarandu. I - Alterações nas características químicas do solo.

Revista Brasileira Ciência do Solo, v.32; p.1591-1599, 2008.
DRUMOND, L. C. D.; ZANINI, J. R.; AGUIAR, A. P. A.; RODRIGUES, G. P.; FERNANDES, A. L. T. Produção de massa seca em pastagem de Tifton 85 irrigada, com diferentes doses de dejeto líquido de suíno. Revista Engenharia Agrícola, v.26; p.426-433, 2006.

EMPRESA BRASILEIRA DE PESQUISA AGROPECUÁRIA EMBRAPA. Centro Nacional de Pesquisa de Solos. Sistema brasileiro de classificação de solos. 3.ed. Brasília: EMBRAPA-SPI / Rio de Janeiro: Embrapa Solos, 2013. 306p.

KIEHL, E. J. Fertilizantes orgânicos. Piracicaba: Agronômica Ceres, 1987. 492p.

LANGE, A.; CARVALHO. J. L. N.; DAMIN, C. J. C.; MARQUES, J. J. Alterações em atributos do solo decorrentes da aplicação de nitrogênio e palha em sistema semeadura direta na cultura do milho. Ciência Rural, v.36; p.460-467, 2006.

MALAVOLTA, E.; VITTI, G.; OLIVEIRA, S. A. Avaliação do estado nutricional de plantas: princípios e aplicações. 2.ed. Piracicaba: Potafós, $1997.319 \mathrm{p}$.

MARTUSCELLO J. A.; FONSECA D. M.; NASCIMENTO JÚNIOR, D. SANTOS, P. M.; CUNHA, D. N. F. V.; MOREIRA, L. M. Características morfogênicas e estruturais de capimMassai submetido à adubação nitrogenada e desfolhação. Revista Brasileira de Zootecnia, v.35, p.665671, 2006.

MARTUSCELLO J. A.; FONSECA D. M.; NASCIMENTO JÚNIOR, D.; SANTOS, P. M.; RIBEIRO JUNIOR, J. I.; CUNHA, D. N. F. V.; MOREIRA, L.M. Características morfogênicas e 
Rev. Bras. Saúde Prod. Anim., Salvador, v.16, n.1, p.23-35 jan./mar., 2015 http://www.rbspa.ufba.br ISSN 15199940

estruturais do capim-Xaraés submetido à adubação nitrogenada e desfolhação.

Revista Brasileira de Zootecnia, v.34, p.1475-1482, 2005.

ORRICO JUNIOR, M. A. P.; ORRICO, A. C. A.; CENTURION, S. R.; SUNADA, N. S.; LUCAS JUNIOR, J. L. Valor nutritivo do capim Piatã adubado com diferentes doses de biofertilizante. Revista Agrarian, v.4, n.21, p.312-319, 2013.

PRIMAVESI, A. C.; PRIMAVESI, O.; CORREAA, L. A.; CANTARELLA, H.; SILVA, A. G. Absorção de cátions e ânions pelo capim Coastcross adubado com ureia e nitrato de amônio. Pesquisa Agropecuária Brasileira, v.40, p.247253, 2005.

PRIMAVESI, A. C.; PRIMAVESI, O.; CORREAA, L. A.; CANTARELLA, H.; SILVA, A. G.; FREITAS, A. R.; VIVALDI, L. J. Adubação Nitrogenada em Capim Coastcross: Efeitos na Extração de Nutrientes e Recuperação Aparente do Nitrogênio. Revista Brasileira de Zootecnia, v.33, p.68-78, 2004.

PRIMAVESI, A. C.; PRIMAVESI, O.; CORRÊA, L. A.; SILVA, A. G.; CANTARELLA, H. Nutrientes na fitomassa de capim-Marandu em função de fontes e doses de nitrogênio. Ciência Agro-técnica, v.30, p.562-568, 2006.

QUAGGIO, J. A.; RAIJ, B. V.; MALAVOLTA, E. Alternative use of the SMP - buffersolution to determine lime of soils. Communication Soil Science Plant Analysis, v.16, p.245260,1985 .

RAIJ, B. Van.; CANTARELLA, H.; ANDRADE, N. O.; QUAGGIO, J. A.; FURLANI, A. M. C. Interpretação de resultados de análise de solo. In: RAIJ,
B. Van.; CANTARELLA, H.; QUAGGIO, J.A.; FURLANI, A.M.C. (Eds). Recomendações de adubação e calagem para o Estado de São Paulo. 2.ed. rev. Campinas: IAC, 1997. p.8-13. (Boletim Técnico, 100).

RASCHID, M. I.;GOEDE, R. G. M.; NUNEZ, G. A. C.; BRUSSAARD, L.; LANTINGA, E. A. Soil $\mathrm{pH}$ and earthworms affect herbage nitrogen recovery from solid cattle manure in production grassland. Soil Biology and Biochemistry, v.68, p.1-8, 2014.

REIJENEVELD, J. A.; ABBINK, G. W.; TERMORSHUIZEN, A. J.; OENEMA, O. Relationships between soil fertility, herbage quality and manure composition on grassland-based dairy farms. Europe Journal Agronomy, v.56, p.9-18, 2014.

ROCHA, G. P.;EVANGELISTA, A. R.;LIMA, J. A.; ROSA, B. Adubação nitrogenada emgramíneas do Gênero Cynodon. Ciência Animal Brasileira, v.3, p.1-10, 2002.

RODRIGUES, L. R. A.; RODRIGUES, T. J. D.; REIS, R. A.; SOARES FILHO, C. V. Produção de matéria seca e composição química de cinco cultivares de Cynodon. Acta Scientiarum Animal Science, v.28, p.251-258, 2006.

SCHIMIDT, L. T.; DIAS, P. F.; SOUTO, S. M.; ROSSIELLO, R. O. P.; ZANINE, A. M.; MACEDO JUNIOR, G. L.; PEREIRA, B. M. Efeitos de doses de N de chorume e épocas de coleta no desenvolvimento do capim Tanzânia. Revista Ciência Agronômica, v.34, p.510, 2003.

SILVA, D. J.; QUEIROZ, A. C. Análise de alimentos: métodos químicos e biológicos. 3.ed. Viçosa, MG: Universidade Federal de Viçosa, 2002. $235 \mathrm{p}$. 
Rev. Bras. Saúde Prod. Anim., Salvador, v.16, n.1, p.23-35 jan./mar., 2015 http://www.rbspa.ufba.br

SILVA NETO, S. P.; SILVA, J. E. C.; SANTOS, A. C.; CASTRO, J. G. D.; DIM, V. P.; ARAÚJO, A. S.

Características agronômicas e nutricionais do capim-Marandu em função da aplicação de resíduo líquido de frigorífico. Acta Scientiarum Animal Science, v.32, p.9-17, 2010.

SOARES FILHO, C. V.; RODRIGUES, L. R. A.; PERRI, S. H. V. Produção e valor nutritivo de dez gramíneas forrageiras na região Noroeste do Estado de São Paulo. Acta Scientiarum Agronomy, v.24, p.1377-1384, 2002.

STATISTICAL ANALYSIS SYSTEM. SAS/STAT Procedure guide personal computers. 9.ed. Cary, NC: SAS

Institute, 1999. 334p.

Van SOEST, P. J. Nutritional ecology of the ruminant. 2.ed. Ithaca: Cornell University Press, 1994, 476p.

VILLA NOVA, N. A.; DETOMINI, E. R.;DOURADO NETO, D.;

MANFRON, P. A.; PEDREIRA, C. G.

S. Modelo de estimativa da produtividade de fitomassa seca de parte aérea de Cynodon nlemfuënsis L. cv. Florico em função da radiação solar. Pasturas Tropicales, v.26, p.56-61, 2004.

WERNER, J. C.; PAULINO, V. T.; CANTARELLA, H.; ANDRADE, N. O.; QUAGGIO, J. A. Forrageiras. In: RAIJ, B. Van.; CANTARELLA, H.; QUAGGIO, J. A.; FURLANI, A. M. C. (Eds). Recomendações de adubação e calagem para o Estado de São Paulo. 2. ed. rev. Campinas: IAC, 1997. p.263273. (Boletim Técnico, 100).

Data de recebimento: 09/05/2014

Data de aprovação: 12/03/2015 